\title{
The Design and Implementation Colleges and Universities Cadres Management System based on J2EE
}

\author{
Ping Chen \\ College of mathematics and computer science Jiangxi Science and Technology Normal University, \\ Nanchang, China \\ e-mail: saydochenping@126.com
}

Keywords: Cadre information; Cadre management; J2EE; Fuzzy evaluation; Ability evaluation

\begin{abstract}
On the basis of cadre management business requirements analysis in colleges and universities, this paper designed and developed one colleges and universities cadres management system with a set of user management, cadres management, cadres ability evaluation and system management based on J2EE platform colleges and universities management system cadres solutions. The system finished college cadre ability qualitative analysis and quantitative evaluation by the method of fuzzy comprehensive judgment. The evaluation result provides decision support for leaders' choice, which truly realized the transformation from "restraining" to "digital speak". This method is scientific, reasonable, and is a good way in cadre evaluation area for reference and popularization.
\end{abstract}

\section{THE INTRODUCTION}

A. Research background and significance

At present, based on the pattern of college office change and rapid development and popularization of computer technology, use computer technology to realize colleges and universities cadres' management is imperative. Colleges and universities cadres management system is in accordance with colleges and universities cadres management process, processes tedious cadre management work and repetitive work to be scientific, systematic and automatic to meet the needs of various kinds of information collection, storage, processing, management and use of demand in cadre information management, cadre ability assessment, cadres appointment or dismissal for the information and standardization management of school personnel information. The decision-making departments at the same time also can conveniently share to the school staff information resources to achieve the effect of get twice the result with half the effort.

B. Main research contents

The colleges and universities cadres' management system is based on J2EE and works in Windows operating platform, combines with $\mathrm{B} / \mathrm{S}$ architecture and MVC framework. Use MyEclipse development tools, and MSSQLServer2000 database. On the basis of comprehensive and in-depth analysis of colleges and universities cadre's management business requirements, design and develop a set of cadre management system including user management, cadres' information management, and cadres' ability evaluation. The paper adopts software engineering method and Struts technology for requirements analysis, software design, software realization and software testing.

C. Related technology introduction

J2EE satisfies various requirements through middle tier integration framework, which can achieve system requirements such as high availability, reliability, scalability and low cost, etc. In addition, J2EE provides a unified development platform for management system concrete application, reduces the complexity of multi-layer system architecture, and can provide strong support for existing applications.

J2EE uses multilayer distributed application mode. Its application logic can be deployed various application components on the same machine according to its functions into components. More often, various application components are on different machines according to their different layer and distributions. J2EE has solved the problems of traditional hierarchy such as hard to upgrade, expansion and maintenance. J2EE typical four layers structure include client layer, Web layer, business logic layer, and cadre management system information database layer run on EIS server. 


\section{SYSTEM REQUIREMENTS ANALYSIS}

A. Cadre management business needs analysis

Colleges and universities cadres' management involves evaluation of cadres' ability, colleges and universities cadres' information, cadre management register, cadres' appointment or dismissal, cadres' management ability. In general, first collect cadres' basic information, learning ability, social skills, leadership, technology level, actual beginning ability information and some evaluation of a person's ability to personality indicators or comprehensive index data obtained by fuzzy judgment. On this basis, the comprehensive evaluation and analysis on the ability of colleges and universities cadres realizes a transformation from qualitative analysis to quantitative analysis to an eligible people. In particular, cadre management process is as follows:

(1) Collect cadre basic information, including name, date of birth, origin, education degree, unit position, resume, etc.

(2) Establish information table: cadre ability evaluation including administrative cadre ability evaluation and teaching cadres ability. In decision-making system, the masses judge the ability of cadres respectively, and input the corresponding evaluation to ability information table.

(3) Establish score information evaluation: input ability information into the information table by administrator's entry, and evaluate the cadres' ability through evaluation system and store the corresponding evaluation score of different position in grade information table. Establish comprehensive evaluation score table: get the comprehensive scores of different position comprehensive score.

(4) Decision support: when policymakers need decision support, check the evaluation score tables, in accordance with the evaluation of different position, query the comprehensive evaluation scores of the cadres.

(5) Decision appointment: decision makers make decisions on the comprehensive evaluation scores, and tell all the cadres.

B. System functional requirements

It includes department information maintenance and adding, modify, delete department information,

etc. Online provide functions such as reserve cadres, cadres and retired cadres' information input,

maintenance, query, delete, statistics and report output. Make the management of personnel

appointed or removed data statistics, personnel appointment management, examination and

approval, appointment document information management. Ability evaluation is the core function

of the systems, including single factor evaluation and integrated evaluation, respectively consider

from their Own CULTURE, PERSONAL FEATURES, SOCIAL SKILLS, LEADERSHIP FOUR ASPECTS.

\section{SYSTEM DESIGN}

Focus on detailed design of user management, cadre information management, appointment or dismissal of cadres' management, and ability evaluation module.

A. Architecture design

The platform is based on J2EE WEB application system, involving J2EE and MVC, Struts, Ajax technology, the biggest advantages of Ajax, which is to maintain the data without update the whole page. The cadre management system adopts MVC three layer architecture based on Struts as shown in Figure 1.

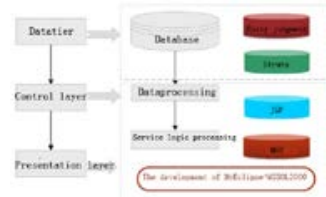

Figure 1 System architecture diagram

\section{B. System function design}

The cadre management system can be divided into 6 big modules: department management, user management, cadre information management, appointment or dismissal of cadres, cadres' capacity evaluation (including the analysis of single factor index and comprehensive index). System maintenance and management, system function structure diagram are shown in Figure 2. 


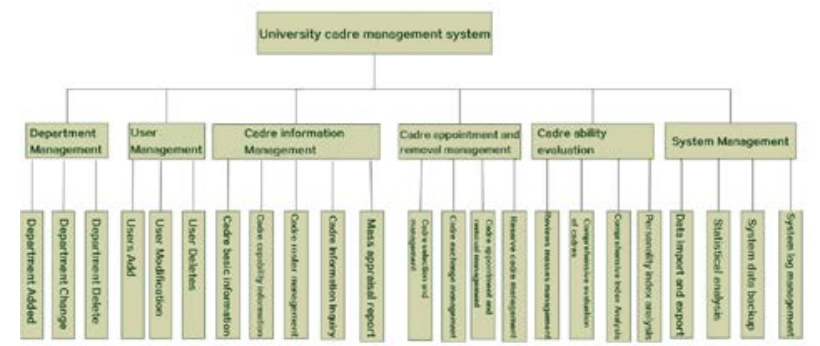

Figure 2 Function structure

C. Detailed design of comprehensive evaluation module

1. Administrative cadres comprehensive evaluation

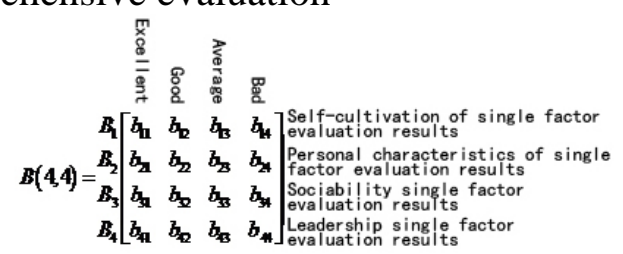

Through single factor evaluation, get each single factor evaluation matrix B $(4,4)$

In module instruction initialization process, comprehensive evaluation set vector matrix is given from very good, better, general to poor matrix $g(4)=\{, 0.671,0.33,0\}$

Calculate fuzzy comprehensive evaluation expectations matrix $\mathrm{E}$ :

$\mathrm{E}=\left(B_{1}, B_{2}, B_{3}, B_{4}\right)^{T} \mathrm{~g}(1)$,

For $\mathrm{I}=1$ to 4

For $\mathrm{j}=1$ to 4

$E(I)=E(I)+B(I, j) \times g(j)$

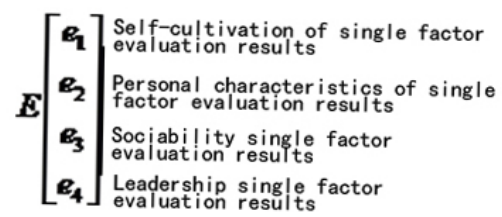

Administrative cadre fuzzy comprehensive evaluation results take centesimal system scores, and weights of comprehensive evaluation in the previous analysis are: $A=(0.35,0.05,0.15,0.35)$

$\mathrm{XZGB}=\mathrm{A} * \mathrm{E} * 100(2)$

namely

For $\mathrm{I}=1$ to 4

$\mathrm{XZGB}=\mathrm{XZGB}+\mathrm{A}(\mathrm{I}) * \mathrm{E}(\mathrm{I})$

2. Technical cadres comprehensive evaluation

Through single factor evaluation, get each single factor evaluation matrix C $(4,4)$

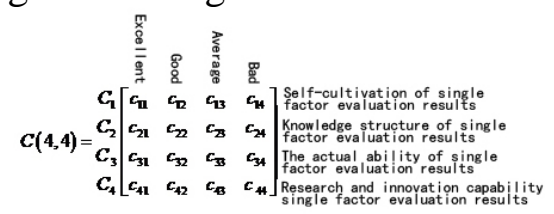

From the above expectations, judgment matrix calculates fuzzy comprehensive evaluation matrix $\mathrm{E}$ :

$\mathrm{E}=\left(C_{1}, C_{2}, C_{3}, C_{4}\right)^{T} \quad \mathrm{~g},(3)$

For $\mathrm{I}=1$ to 4

For $\mathrm{j}=1$ to 4

$E(I)=E(I)+C(I, j) \times g(j)(4)$

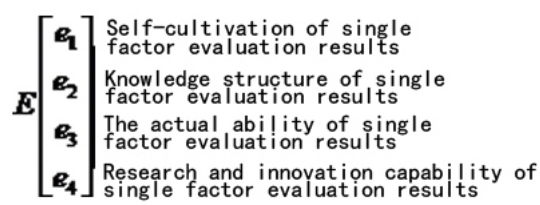

Technical cadres fuzzy comprehensive evaluation results use centesimal system scores, and weights of comprehensive evaluation in the previous analysis is: $\mathrm{A}=(0.2,0.2,0.3,0.2)$ 
JSGBGB $=\mathrm{A} * \mathrm{E} * 100(5)$

namely

For $\mathrm{I}=1$ to 4

JSGBGB $=$ JSGBGB + A (I) * E (I) (6)

D. Database design

Conceptual structure design independence and actual data structure of data model, conceptual structure turns into a logical structure; we can design database physical structure. This transition includes entity tables' transformation and relational transformation. Through analysis, the system database e-r diagram is shown in Figure 3:

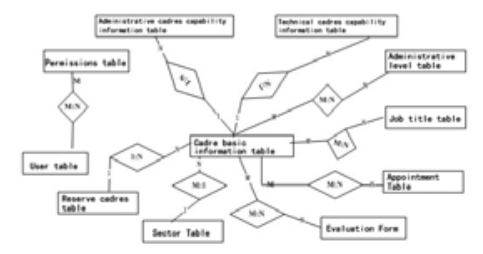

Figure 3 System database e-r diagram (partial)

First choose topical application, then design local view, finally, integrate the partial view to conceptual schema.

\section{SYSTEM IMPLEMENTATION}

\section{A. Department management}

Provide institutional daily maintenance function, use XML tree structure for tree display department, and support right key operation. Administrators can click on the tree branch node to display detailed information, and add, delete, modify, also add employees to department on the tree structure.

B. Cadre information management

Cadres basic information management includes cadre information add, modify, delete, and query function.

C. Cadre ability evaluation

1. Technology cadre single factor evaluation

Technical cadres' knowledge structure is discussed for example. Technical cadre knowledge structure evaluation develops from six aspects: education experience, degree, professional class average grades, professional basic course grade point average, professional education and foreign language level, and their weights are $0.2,0.3,0.15,0.15,0.1,0.1$, (factors weight data are from personnel department).

For technical cadres knowledge structure evaluation, each technical cadres must fill in technical cadre evaluation form for evaluation, and the system will produce comrade production evaluation matrix (6 x 5matrix). The matrix line expresses evaluation opinions on the factors "very good", "good", "general", "poor" and "bad", and then multiplied each line by $(1,0.75,0.5,0.25,0)$, get college evaluation results of single factor.

2. Technology cadres' comprehensive evaluation

After completion of single factor evaluation, technical cadres' comprehensive evaluation can be performed. These evaluation factors include cadre own recuperation, knowledge structure, practical ability and scientific research and innovation ability. Their weights are 0.35, 0.05, 0.15, 0.45, (the factors weight data are from personnel department). Multiply the results of single factor evaluation and weighting matrix, and get the result of comprehensive evaluation.

\section{SYSTEM TEST}

A. Functional test

System function test includes user management, including the administrator log-in function test, function test and fuzzy comprehensive evaluation, (such as personal characteristic ability judgment, their self-cultivation ability judgment, social evaluation ability, leadership evaluation). Test cases add users; enter user name, password, and user level. User name and password must be composed of 10 alphanumeric, and the heading must be letters. For each input (check the validity of user name, password, and user level). User level must be composed of two numbers. Specifically, add user test case design example is shown in Table 1.1. 
Table 1.1 User management add user test cases example

\begin{tabular}{|c|c|c|c|}
\hline Test data & Expected results & Actual result & Result analysis \\
\hline zzy1025483 & add error & add error & $\begin{array}{l}\text { User name right but the } \\
\text { user name is already } \\
\text { existed }\end{array}$ \\
\hline & User name empty & add error & user name cannot be empty \\
\hline Zhangzhao483 & user name is too long & add error & $\begin{array}{l}\text { user name cannot be more } \\
\text { than } 10\end{array}$ \\
\hline 123zh & user name input wrong & add error & $\begin{array}{l}\text { User name cannot begin } \\
\text { with numbers }\end{array}$ \\
\hline Zha一@ & user name input wrong & add error & $\begin{array}{l}\text { user name must begin with } \\
\text { alphanumeric }\end{array}$ \\
\hline Zzy1025483 & add right & add error & user name is correct \\
\hline 11 & user name is correct & expected results right & user level is 2 digits \\
\hline 1 & user level input wrong & enter valid & $\begin{array}{l}\text { number must be two } \\
\text { characters }\end{array}$ \\
\hline 123 & user level input wrong & Expected resultsright & $\begin{array}{l}\text { user level can't be more } \\
\text { than two }\end{array}$ \\
\hline A1 & user level input wrong & expected results right & $\begin{array}{l}\text { user level must be } \\
\text { number }\end{array}$ \\
\hline
\end{tabular}

B. System performance test

In actual development, data throughput ability and response time performance index are also very important. They can reflect the running performance of the system. There are many factors influencing the response speed of the software. Some are because the algorithm is not efficient enough, and some may be affected by the number of concurrent users.

\section{SUMMARY}

Based on the comprehensive and in-depth analysis of colleges and universities cadre management business needs, this paper puts forward the solution of cadre management system under J2EE platform. Software engineering methods and Struts technology are carried for feasibility research, requirement analysis, software design and implementation, designs and develops the colleges and universities cadres management system of user management, cadres management, cadres evaluation, and system maintenance. The system adopts fuzzy comprehensive judgment method to complete administrative ability and teaching evaluation of business process and functional requirements, and gives corresponding system data model. The cadre management system simplifies the difficulty of cadre management as far as possible with strong practicability, easy operation and stable running. It has very good practical applications to avoid man-made factors interference and achieves relatively fair, fair and open.

\section{REFERENCE}

[1] Zheng Qing. Cadre management system design and implementation in Jiangxi college of traditional Chinese medicine [D]. Master Thesis, University of Electronic Science and Technology, 2011 [2]

[2] Chen Yongbao. The design and implementation of document flow system based on workflow [D]. Master Thesis, University of Electronic Science and Technology, , 2010

[3] Hu Zhidan. Personnel information management system design and implementation based on fuzzy evaluation [D]. Master Thesis, Northeastern University, 2008

[4] Shi Cunsheng. The design and implementation of professional skill test system based on B/S structure [D]. Master Thesis, Heilongjiang University, 2010

[5] Cheng Jiangke. Panzhihua college student information management system design and implementation [D]. Master Thesis, University of Electronic Science and Technology, , 2008

[6] Zhang Jiaxiu. Fuzzy comprehensive evaluation method application in statistical analysis [J]. Journal of Anhui Technical Teachers College, 2004, 18 (6) 48-50. 
[7] Miles, R.S. Now Designing Strategic Human Resource Systems.Org anizational Dynamics, 1984

[8] Chen Yongbao. The design and implementation of document flow system based on workflow [D]. Master Thesis, University of Electronic Science and Technology, 2010

[9] Huang Feiyi. Inventory management system based on distributed database [D]. Master Thesis, University of Electronic Science and Technology, , 2011

[10] Du Xuezhen. Colleges and universities management cadre ability examination and its information system [D]. China Agricultural University, 2003

[11] Mou Xiangyu. Transportation charges and fees collection management system based on J2EE [D]. Master Thesis, Chongqing University, 2009 